\title{
An analytical investigation for optimizing the support stiffness and positions of the bearings of a flexible rotor system
}

Jing Liu ( $\nabla$ jliu@cqu.edu.cn )

Chongqing University https://orcid.org/0000-0003-2323-3475

Changke Tang

Chongqing University

\section{Original Article}

Keywords: Bearing stiffness optimization, bearing positions optimization, analytical model , vibrations, flexible rotor system

Posted Date: September 9th, 2020

DOI: https://doi.org/10.21203/rs.3.rs-20831/v2

License: (c) (i) This work is licensed under a Creative Commons Attribution 4.0 International License.

Read Full License 
The authors have withdrawn this preprint from Research Square 